\title{
The L Form of Neisseria meningitidis
}

\author{
By R. B. ROBERTS AND RUTH G. WITTLER \\ Department of Bacteriology, Division of Communicable Diseases and \\ Immunology, Walter Reed Army Institute of Research, Washington, D.C., U.S.A.
}

(Received 13 December 1965)

\begin{abstract}
SUMMARY
$\mathbf{L}$ forms were produced by the penicillin gradient plate technique from four strains of Neisseria meningitidis. All strains were group B and had various sulphadiazine sensitivities. One parent strain had been propagated for many years in the laboratory, whereas the other three were isolated from recent cases of meningitis. To date, each $\mathrm{L}$ form has had more than 60 serial passages on medium containing penicillin. From two strains stabilized $\mathbf{L}$ form variants developed on penicillin-free medium following 30 or $\mathbf{4 0}$ such passages. Morphological characteristics of these organisms were similar to $L$ forms of other bacteria. Medium and environmental conditions necessary for optimal growth included: brain heart infusion containing a final agar concentration of $1.2 \%(w / v)$, sucrose, $10 \%(w / v)$, horse serum, $10 \%(\mathrm{v} / \mathrm{v}), \mathrm{pH} 7 \cdot 4$, temperature $37^{\circ}$ and increased $\mathrm{CO}_{2}$ tension (candle jar). The $L$ forms were non-groupable and had various fermentative reactions, whereas their sensitivity to sulphadiazine was the same as that of their respective parents. Revertants were produced on penicillin-free medium following every tenth serial passage in the L-form state. Sensitivities to sulphadiazine, fermentative reactions and serological groups of the revertant strains were identical with those of their respective parents.
\end{abstract}

\section{INTRODUCTION}

The induction of $\mathrm{L}$ forms by modifications of the gradient plate technique described by Sharp (1954) has been reported by many investigators (Lederberg \& St Clair, 1958; Madoff \& Dienes, 1958). Penicillin has been the inducing agent most commonly used, though other antibiotics such as bacitracin (Rotta, Karakawa \& Krause, 1965), cycloserine (Ward \& Martin, 1962) and cephalosporin (Williams, 1963), have also been used. Although $L$ forms from a number of bacteria have been produced by this method, the successful production and propagation of $\mathrm{L}$ forms of Neisseria meningitidis have not been previously reported. In recent years a high carrier rate and an increasing number of clinical meningococcal infections have been noted in the United States (Bristow, Van Peenen \& Volk, 1965; Brown \& Condit, 1965; Communicable Disease Center, 1964). Because of the possibility that $L$ forms may persist both during prophylaxis and in recurrent meningococcal disease, the present study was undertaken. This paper describes the in vitro production and propagation of $\mathrm{L}$ forms from four strains of Neisseria meningitidis. Morphological characteristics and optimal growth requirements are described. Serological groups, carbohydrate fermentations, and sulphadiazine sensitivities of the parent organisms are compared with those of their respective $\mathbf{L}$ forms and revertants. 


\section{METHODS}

Organisms. Three of the four strains of Neisseria meningitidis used in this study were obtained from the Department of Bacteriology, Walter Reed Army Institute of Research, Washington, D.C., U.S.A. These strains (78-Eur., 79-Eur., 55-III, hereafter designated 78, 79, 55) were recently isolated (April 1965) from the blood of patients with meningitis. Two of the patients were stationed in Europe, the third in the United States. The fourth strain (Ne 15) was kindly sent to us by Dr B. W. Catlin (Marquette University School of Medicine, Milwaukee, Wisconsin). This strain was originally isolated in 1955 from the spinal fluid of a fatal case of nonepidemic meningitis (Catlin \& Cunningham, 1961). Since then it has been repeatedly subcultured on artificial media and is now considered to be a 'laboratory strain'. All four strains were group $\mathbf{B}$ and had identical fermentative reactions.

Media. The standard medium used for the production and propagation of the $\mathrm{L}$ forms was Difco brain heart infusion broth (BRHIB) to which was added Difco agar, $1.2 \%(w / v)$, sucrose, $10 \%(w / v)$, Difco yeast extract, $0.5 \%(w / v)$, and heated $\left(60^{\circ}\right.$ for $30 \mathrm{~min}$.) horse serum, $10 \%(\mathrm{v} / \mathrm{v})$. Benzylpenicillin (Charles Pfizer and Co., Inc., New York), 1000 units/ml., was added to the complete medium to maintain unstable organisms in the $\mathrm{L}$ form. This enriched agar medium containing benzylpenicillin, unless otherwise noted, is designated BRHIA. Penicillin was not added to the medium for the propagation of stable $\mathrm{L}$ forms. BRHIA was prepared weekly. To test sterility freshly prepared medium was incubated at $37^{\circ}$ for $24 \mathrm{hr}$ before storage at $4^{\circ}$.

To determine range and optimal conditions necessary for growth of meningococcal $\mathrm{L}$ forms, colonies were transferred for five serial passages on various media and the degree of growth noted. Growth was tested on three types of base medium; BRHIA, Difco heart infusion agar (HIA) and Baltimore Biological Laboratories (BBL) Trypticase agar (TA). Sodium chloride, 2 or $4 \%(\mathrm{w} / \mathrm{v})$, and sucrose, 10 or $20 \%$ $(w / v)$, were compared for osmotic stabilization. The effect on L-form growth of sera from horse, rabbit and man was also compared. Growth was evaluated on agar concentrations of $0 \cdot 7-2 \cdot 4 \%(w / v)$, at temperatures of $25-4.1^{\circ}$, in three gaseous environments (candle jar, aerobic, anaerobic) and in the range $\mathrm{pH}$ 5.5-11.0. The $\mathrm{pH}$ value of the medium was adjusted by adding either $0.1 \mathrm{~N}-$ or $0.5 \mathrm{~N}-\mathrm{HCl}$ or $\mathrm{NaOH}$.

Parent and revertant meningococci were subcultured either in BBL Eugonbroth or on Difco Mueller-Hinton chocolate agar.

Production and propagation of $L$ forms. As the initial step in the production of $\mathrm{L}$ forms, a 12-18 hr growth of meningococci was inoculated into $20 \mathrm{ml}$. of Eugonbroth. This broth was placed on an Eberbach reciprocating shaker (6500 osc./hr), and incubated aerobically at $37^{\circ}$ for $6-8 \mathrm{hr}$. Penicillin-free BRHIA plates ( $100 \times$ $15 \mathrm{~mm}$.) in which a $5 \times 50 \mathrm{~mm}$. trough had previously been made were inoculated with $0.3 \mathrm{ml}$. of this broth culture. After distributing the inoculum over the surface of the agar, $\mathbf{0} \cdot 25 \mathrm{ml}$. of benzylpenicillin $(\mathbf{1 0 0 , 0 0 0}$ units $/ \mathrm{ml}$.) was placed in the trough. Plates were incubated at $37^{\circ}$ in candle jars containing moist gauze and were examined each day for 10 days under a colony microscope. When L-form growth was present, blocks of agar containing L-form colonies were cut out with a small metal spatula, inverted onto fresh BRHIA plates and streaked with the spatula 
or a sterile glass rod. Subsequent cultures were then transferred in duplicate every 2-3 days. For future studies, several agar blocks containing a heavy growth of L-form colonies were frozen with acetone and dry ice following each 10th serial passage and immediately stored at $-20^{\circ}$.

Reversion of $L$ forms. Following every 10th serial passage, agar blocks containing L-form colonies were transferred to BRHIA without penicillin and subcultured until bacterial forms appeared. These revertant organisms were then transferred to Mueller-Hinton chocolate agar and subsequently freeze-dried.

Morphology of $L$ forms. The morphological characteristics of $L$-form colonies were studied by two methods: (1) examination of unstained colonies with the colony microscope (magnification $\times 45)$; $(2)$ by the stained agar technique of Dienes (Madoff, 1960) with phase contrast microscopy.

Serological grouping, carbohydrate fermentation and sulphadiazine sensitivity of $L$ forms and revertants. Two methods were used in the preparation of L-form antigens for group determinations. In the first method L-form colonies were cultured on BRHIA containing $10 \%(\mathrm{v} / \mathrm{v})$ rabbit serum instead of horse serum. After three serial passages, growth was removed from the surface of the agar with a sterile cottonwool swab and suspended in normal saline.

The second method was as follows. After three serial passages on BRHIA containing $10 \%(\mathrm{v} / \mathrm{v})$ rabbit serum, large agar blocks with L-form growth were transferred to flasks containing $25 \mathrm{ml}$. BRHIA. The inoculated agar was then overlayed with $10 \mathrm{ml}$. of BRHIB containing $0.01 \%(\mathrm{w} / \mathrm{v})$ agar, $10 \%(\mathrm{w} / \mathrm{v})$ sucrose, $0.5 \%(\mathrm{w} / \mathrm{v})$ Difco yeast extract and 1000 units benzylpenicillin $/ \mathrm{ml}$. Both the agar and broth contained $10 \%(\mathrm{v} / \mathrm{v})$ rabbit serum. On the third and sixth day after inoculation $\mathbf{0 . 2} \mathrm{ml}$. of broth was subcultured on BRHIA. Following incubation for $48 \mathrm{hr}$, these subcultures were in turn transferred to other flasks with diphasic media. This procedure was repeated until a heavy growth of L-form colonies appeared in the broth. Organisms from the $10 \mathrm{ml}$. of broth were sedimented by centrifugation, washed once and resuspended in physiological saline. The concentration of the final suspensions prepared by both methods was equivalent to a MacFarland optical density standard no. 3. Difco meningococcus antiserum was used for grouping by the usual macroscopic slide and tube agglutination techniques. Controls included both normal saline and normal rabbit serum.

Carbohydrate fermentations were determined on HIA medium by using the method of Edward (1950). The medium also contained $\mathrm{NaCl} 2 \%(w / v)$, horse serum $10 \%(\mathrm{v} / \mathrm{v})$, test carbohydrate $1.0 \%(\mathrm{w} / \mathrm{v})$, phenol red $0.005 \%(\mathrm{w} / \mathrm{v})$, and benzylpenicillin 1000 units/ml. Carbohydrates were not added to the control medium.

Sensitivity to sulphadizaine was determined on BRHIA without penicillin. Both the $\mathrm{L}$ form and its respective parent were subcultured on medium containing various concentrations of sulphadiazine and the minimum inhibitory concentration (m.i.c.) determined.

All revertant meningococci were identified by the following methods: (1) Gram stain; (2) grouping with meningococcus antiserum; (3) fermentative reactions and sulphadiazine sensitivities determined by the method of Evans, Hunter, Cary \& Rust (1964). 


\section{RESULTS}

\section{Production and propagation of $L$ forms}

Following the inoculation of penicillin gradient plates with a broth culture of the parent meningococcus, L-form colonies appeared in 3-5 days. The number of colony forming units varied from 1 to 30 per plate. When agar blocks containing colonies were transferred to BRHIA, propagation of these colonies generally did not occur. Organism 78 was an exception, and these $\mathrm{L}$ forms propagated well following the first passage.

When growth did not occur in 8-10 days, the previously transferred agar blocks were again streaked across the surface of the same agar plate. Within 4-6 days, growth appeared at the previous site of the block though colonies were not evident along the streak pathway. These $\mathbf{L}$ colonies were then transferred to BRHIA without penicillin for reversion. The revertants designated $79 \mathrm{R}, \mathrm{Ne} 15 \mathrm{R}, 55 \mathrm{R}$ were subcultured in Eugonbroth and inoculated onto gradient plates. Within 2-4 days, a heavy growth of $\mathbf{L}$ colonies appeared in a band-like pattern between the penicillin trough and bacterial growth (Pl. 1, fig. 1). Non-propagating, small, rough bacterial colonies were also seen in this area (PI. 1, fig. 2). On subsequent transfer, the L-form colonies propagated well, growth being apparent within $24 \mathrm{hr}$, and welldeveloped colonies were present in $48 \mathrm{hr}$. At the time of writing this report these $\mathrm{L}$ forms had had at least 60 serial passages on BRHIA.

In general, all revertant bacteria produced a significantly greater number of $\mathrm{L}$ forms than their respective parents. This property was maintained even after repeated subculture $(\times 45)$ of the revertants on Mueller-Hinton chocolate agar.

To test L-form stability BRHIA cultures were transferred to penicillin-free medium from every 10th serial passage. Initially all L-form colonies reverted to bacteria. Selected stabilized variants of $L$ forms 78 and 55 first developed in penicillin-free subcultures from the 30th and 40th serial passage, respectively, and at the time of this report these variants had had 30 transfers on BRHIA without penicillin. By the 60th serial passage on BRHIA, all $\mathrm{L}$ form colonies of strain 78 were stable following subsequent transfer to penicillin-free medium. To date all $\mathrm{L}$ form colonies of organisms 79 and $\mathrm{Ne} \mathbf{1 5}$ have continued to revert to bacteria by the third passage on penicillin-free medium.

\section{Growth requirements of $L$ forms}

Range and optimal conditions necessary for growth of meningococcal $\mathrm{L}$ forms are shown in Table 1 . Though $L$ forms propagated on all three types of base medium (BRHIA, HIA, TA), optimal growth occurred on BRHIA. Growth was also tested on media that contained final agar concentrations of $0 \cdot 7-2 \cdot 4 \%(w / v)$. Growth occurred over a range of $0 \cdot 8-1 \cdot 8 \%(\mathrm{w} / \mathrm{v})$ agar with optimum growth on $1 \cdot 0-1 \cdot 6 \%$ $(w / v)$. On $2 \cdot 0-2 \cdot 4 \%(w / v)$ agar medium, $L$ forms reverted to bacteria even in the presence of penicillin.

$\mathrm{L}$ forms did not propagate unless an osmotic stabilizing agent was present in the medium. Although propagation occurred with a concentration of $2 \%(w / v) ~ N a C l$, $4 \%(\mathrm{w} / \mathrm{v}) \mathrm{NaCl}$ completely inhibited $\mathrm{L}$ form growth. Sucrose, on the other hand, was equally effective in supporting growth at a $10 \%$ or $20 \%(w / v)$ concentration. 
Serum was also necessary for the propagation of $\mathrm{L}$ forms. Unheated serum appeared to be as effective as heated serum, and growth occurred equally well on media containing serum derived from horse, rabbit or man. In the first several passages, growth was less abundant when $\mathrm{L}$ forms were transferred from medium containing one species of animal serum to another. Horse serum concentrations ranging from 1 to $20 \%(\mathrm{v} / \mathrm{v})$ appeared to be equally effective in L-form propagation.

Table 1. Growth requirements for L forms of Neisseria meningitidis

\begin{tabular}{|c|c|c|}
\hline Requirement & Range & Optimum \\
\hline Base media & $\begin{array}{l}\text { Brain heart infusion } \\
\text { Heart infusion agar } \\
\text { Trypticase agar }\end{array}$ & Brain heart infusion \\
\hline Agar \% (w/v) & $0 \cdot 8-1 \cdot 8$ & $1 \cdot 0-1 \cdot 6$ \\
\hline Osmotic stabilization & $\begin{array}{l}\text { Sucrose } \\
\mathrm{NaCl}\end{array}$ & Sucrose \\
\hline Serum & $\begin{array}{l}\text { Horse } \\
\text { Rabbit } \\
\text { Human }\end{array}$ & $\begin{array}{l}\text { Horse } \\
\text { Rabbit } \\
\text { Human }\end{array}$ \\
\hline pH & $6 \cdot 0-9 \cdot 5$ & $7 \cdot 0-8 \cdot 5$ \\
\hline Environment & $\begin{array}{c}\mathrm{CO}_{2} \text { (candle jar) } \\
\text { Aerobic }\end{array}$ & $\mathrm{CO}_{2}$ (candle jar) \\
\hline Temperature & $29-39^{\circ}$ & $34-38^{\circ}$ \\
\hline
\end{tabular}

The range of $\mathrm{pH}$ values in which growth occurred was $\mathrm{pH} 6 \cdot 0-9 \cdot 5$ with an opti-

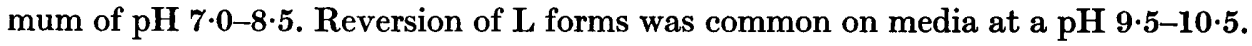
Since the unaltered $\mathrm{pH}$ value of freshly prepared BRHIA was $\mathrm{pH} \mathbf{7 \cdot 3 - 7 \cdot 4}$, no adjustment was necessary for the routine cultivation of these organisms. $L$ form propagation was also tested in three different environments: candle jar, aerobic and anaerobic environment. Growth was superior in the presence of extra $\mathrm{CO}_{2}$ (candle-jar), and L-form propagation did not take place in an anaerobic environment. The concentration of the $\mathrm{CO}_{2}$ in candle jars was not measured. Finally, cultures were incubated at temperatures ranging from 25 to $41^{\circ}$. Growth occurred in the range $29-39^{\circ}$, though organisms did not propagate well at either temperature extreme. For optimal growth the temperature range was $34-38^{\circ}$.

\section{Morphology of $L$ forms}

Two types of L-form colonies were seen. The first type of colony contained little or no periphery and had a poorly developed core which did not penetrate well into the agar. When transferred, these cores tended to break apart and propagation did not occur. This type of L-form colony was characteristic of those seen on gradient plates inoculated with the parent bacterium.

The second type of L-form colony had a well-demarcated core which penetrated into the agar and a sharply defined periphery (Pl. 1, fig. 3). The core of this type of colony remained intact during agar transfer and colony propagation was excellent. The appearance of these colonies and the relative size of the core to periphery varied widely in the same culture ( $\mathrm{Pl}$. 1, fig. 4). Colony size, determined by duration of growth and degree of colony crowding, varied between 50 and $500 \mu$. When stained and observed under higher magnification (Pl. 2, fig. 5), structural elements were 
indistinguishable from those of $\mathbf{L}$ form colonies of other bacteria. These structures included granular bodies which characteristically were found in the core of the colony and vacuoles which were primarily seen in the periphery. Phase microscopy defined these structures even more clearly (Pl. 2, figs. 6-8). Granular bodies varied in size (Pl. 2, fig. 7) and were also present both between and within the peripheral vacuoles (Pl. 2, fig. 8). The density of these vacuoles appeared homogenous and their boundaries were distinct (Pl. 2, fig. 8). Intermediate sized, phase-dense bodies were also seen throughout the periphery (Pl. 2, fig. 6).

\section{Serological grouping, fermentative reactions, sulphadiazine sensitivity and Gram staining of $L$ forms and revertants}

Comparison of serological grouping, fermentative reactions and sulphadiazine sensitivity of $\mathrm{L}$ forms and of their respective parents is shown in Table 2. Suspensions of parent bacteria agglutinated with group B antisera. $\mathrm{L}$ form antigens whether harvested from agar or from broth did not agglutinate with polyvalent or groups $\mathrm{A}, \mathrm{B}$, or $\mathrm{C}$ antisera. Both normal serum and saline controls were negative.

Table 2. Comparison of parent meningococci with their respective $L$ forms

\begin{tabular}{|c|c|c|c|c|c|}
\hline \multirow[b]{2}{*}{ Organism no. } & \multirow[b]{2}{*}{ Group } & \multicolumn{3}{|c|}{ Sugar fermentation } & \multirow{2}{*}{$\begin{array}{c}\text { Sulphadiazine } \\
\text { sensitivity } \ddagger \\
\text { (mg./100 ml.)* }\end{array}$} \\
\hline & & Glucose & Maltose & Sucrose & \\
\hline $\begin{array}{l}\text { Parent } 78 \\
\text { (1) } L \text { form } \\
\text { (2) Stabilized L form }\end{array}$ & $\begin{array}{l}\text { B } \\
\text { N-g. } \dagger \\
\text { N-g. }\end{array}$ & $\begin{array}{l}+ \\
+ \\
+\end{array}$ & $\begin{array}{l}+ \\
+ \\
+\end{array}$ & $\begin{array}{l}- \\
- \\
-\end{array}$ & $\begin{array}{l}0 \cdot 05 \\
\text { No change } \\
\text { No change }\end{array}$ \\
\hline $\begin{array}{c}\text { Parent } 79 \\
\mathrm{~L} \text { form }\end{array}$ & $\begin{array}{c}\text { B } \\
\text { N-g. }\end{array}$ & $\begin{array}{l}+ \\
+\end{array}$ & $\begin{array}{l}+ \\
+\end{array}$ & - & $\begin{array}{c}0.05 \\
\text { No change }\end{array}$ \\
\hline $\begin{array}{l}\text { Parent } \mathrm{Ne} 15 \\
\mathrm{~L} \text { form }\end{array}$ & $\begin{array}{c}\text { B } \\
\text { N-g. }\end{array}$ & $\begin{array}{l}+ \\
\pm\end{array}$ & $\begin{array}{l}+ \\
\pm\end{array}$ & $\overline{-}$ & $\begin{array}{c}0.05 \\
\text { No change }\end{array}$ \\
\hline $\begin{array}{l}\text { Parent } 55 \\
\text { (1) L form } \\
\text { (2) Stabilized L form }\end{array}$ & $\begin{array}{l}\text { B } \\
\text { N-g. } \\
\text { N-g. }\end{array}$ & $\begin{array}{l}+ \\
+ \\
+\end{array}$ & $\begin{array}{l}+ \\
+ \\
+\end{array}$ & $\begin{array}{l}- \\
-\end{array}$ & $\begin{array}{l}\quad 4.0 \\
\text { No change } \\
\text { No change }\end{array}$ \\
\hline
\end{tabular}

All parent meningococci produced acid from glucose and maltose but not from sucrose. $\mathrm{L}$ forms from organisms 78, 79 and 55 had fermentative reactions identical to those of their respective parents. These reactions were manifested by a permanent yellow colour change of the entire medium within 2 days after plate inoculation. The $\mathrm{L}$ form of Ne $\mathbf{1 5}$ produced a colour change only beneath the inoculating agar block. Fermentative reactions were tested with both recently produced $\mathrm{L}$ forms and $\mathrm{L}$ forms which had had 50 serial passages. The degree of fermentation in each group was the same. All control plates were negative.

Initial sulphadiazine sensitivity values of the parent organisms were determined by the method of Evans et al. (1964). These results, expressed as minimal inhibitory dose (m.i.c.) in $\mathrm{mg}$./100 ml., are shown in Table 2. L-form sensitivity values were determined on penicillin-free BRHIA plates which contained various concentrations of sulphadiazine. Each plate was also inoculated with the parent organism. 
On this medium the $\mathbf{L}$ form and its parent bacterium had identical sulphadiazine sensitivities. A comparison of these three properties in revertant bacteria and parent organisms is shown in Table 3. Serological grouping, carbohydrate fermentation and sulphadiazine sensitivity of the revertant strains were identical to those of their respective parent bacterium.

Bacteria were not seen in repeated Gram stains of L-form colonies. When Gram stains were performed on recently reverted bacteria, these organisms varied in size, shape and intensity of staining. However, following several transfers on MuellerHinton chocolate agar, the morphology and staining properties of these organisms were identical with those of typical meningococci.

Table 3. Comparison of parent meningococci with their respective revertants*

\begin{tabular}{|c|c|c|c|c|c|}
\hline \multirow[b]{2}{*}{ Organism no. } & \multirow[b]{2}{*}{ Group } & \multicolumn{3}{|c|}{ Sugar fermentation } & \multirow{2}{*}{$\begin{array}{l}\text { Sulphadiazine } \\
\text { sensitivity } \\
(\mathrm{mg} . / 100 \mathrm{ml} .) \dagger\end{array}$} \\
\hline & & Glucose & Maltose & Sucrose & \\
\hline $\begin{array}{l}\text { Parent } 78 \\
\text { Revertants }\end{array}$ & $\begin{array}{l}\mathbf{B} \\
\mathbf{B}\end{array}$ & $\begin{array}{l}+ \\
+\end{array}$ & $\begin{array}{l}+ \\
+\end{array}$ & - & $\begin{array}{l}0 \cdot 05 \\
0 \cdot 05\end{array}$ \\
\hline $\begin{array}{l}\text { Parent 79 } \\
\text { Revertants }\end{array}$ & $\begin{array}{l}\mathbf{B} \\
\mathbf{B}\end{array}$ & $\begin{array}{l}+ \\
+\end{array}$ & $\begin{array}{l}+ \\
+\end{array}$ & - & $\begin{array}{l}0.05 \\
0.05\end{array}$ \\
\hline $\begin{array}{r}\text { Parent Ne } 15 \\
\text { Revertants }\end{array}$ & $\begin{array}{l}\mathbf{B} \\
\mathbf{B}\end{array}$ & $\begin{array}{l}+ \\
+\end{array}$ & $\begin{array}{l}+ \\
+\end{array}$ & - & $\begin{array}{l}0.05 \\
0.05\end{array}$ \\
\hline $\begin{array}{l}\text { Parent 55 } \\
\text { Revertants }\end{array}$ & $\begin{array}{l}\mathbf{B} \\
\mathbf{B}\end{array}$ & $\begin{array}{l}+ \\
+\end{array}$ & $\dot{+}$ & - & $\begin{array}{l}4.0 \\
4 \cdot 0\end{array}$ \\
\hline
\end{tabular}

* Revertants were produced from every 10th serial passage of unstable $L$ forms.

$\uparrow$ Minimum inhibitory concentration.

\section{DISCUSSION}

The successful production of $\mathrm{L}$ forms of Neisseria meningitidis was achieved in this work by using the penicillin gradient plate technique. Possibly the single most important factor in obtaining augmented production and serial propagation of $\mathbf{L}$ forms was the use of revertant meningococci for re-inoculation of gradient plates. This in vitro method proved simple and generally effective, and $\mathrm{L}$ forms from both old and new isolates were readily obtained. More recent studies in this laboratory indicate that the technique is equally applicable to production of $\mathbf{L}$ forms from group A and group C meningococci. Our methods differed widely from those described in previous reports in which $\mathrm{L}$ forms of neisseria from clinical sources could not be isolated and subsequently propagated (Dienes \& Weinberger, 1951; Dienes, Bandur \& Madoff, 1964).

To facilitate biochemical and serological studies of these $\mathbf{L}$ forms, optimal growth requirements were determined. In some instances these requirements, such as animal serum, agar concentration, $\mathrm{pH}$ of medium and gaseous environment, were similar to those that have previously been described for other $\mathbf{L}$ forms. Though studies on nutritional requirements of $L$ forms are few, the need for animal serum for growth of certain $L$ forms has been well established (Edward, 1953) and has also proved necessary for the growth of meningococcal $\mathbf{L}$ forms. High concentrations of agar promoting L-form reversion were first described by Landman \& Halle (1963). They reported that agar concentrations of $2 \cdot 0-2 \cdot 5 \%(w / v)$ favoured reversion of 
L forms of Bacillus subtilis. Dr Gooder (personal communication) has found that reversion of Streptococcus faecalis $L$ forms occurs on $2 \cdot 5 \%(w / v)$ agar. These findings were also characteristic of $L$ forms of meningococci. Edward (1950) reported that L forms of Streptobacillus moniliformis grew well on media in the range pH 6.8-9.2; growth on a more acid or alkaline medium was not tested. Smith (1964) stated that loss of L-form viability occurred when the medium was less than $\mathrm{pH} \mathrm{7 \cdot 0}$ or greater than $9 \cdot 0$. Our results were in general agreement with these two reports, since L-form propagation was observed in a range $\mathrm{pH} \mathrm{6.0-9.5}$ and optimal growth occurred at $\mathrm{pH} 7 \cdot 0-8 \cdot 5$. To our knowledge, reversion of $\mathrm{L}$ forms on a high alkaline medium (pH 9.5-10.5) has not previously been reported. It has also been stated that the gaseous requirement for L-form growth is the same as that for the parent bacterium (Dienes \& Weinberger, 1951). The growth of parent meningococci and their respective $\mathrm{L}$ forms was superior in the presence of extra $\mathrm{CO}_{2}$, whereas neither organism propagated in an anaerobic environment.

Differences in growth requirements between meningococcal and other $\mathrm{L}$ forms were also apparent. For growth of certain $\mathbf{L}$ forms, media with high concentrations of salt are required (Smith, 1964). $\mathrm{NaCl} 4 \%(\mathrm{w} / \mathrm{v}$ ) inhibited growth of meningococcal L forms, whereas sucrose supported growth at both concentrations tested. The optimal temperature for growth of other $\mathrm{L}$ forms has not been reported, though it has been suggested that the temperature should be the same as that for the parent bacterium (Smith, 1964). Studies in this laboratory demonstrated that parent meningococci grow at temperatures of $25-40^{\circ}$. The range for growth of meningococcal $\mathrm{L}$ forms was $29-39^{\circ}$, though optimal growth occurred only at $34-38^{\circ}$. Quantitative studies to define further the growth requirements of meningococcal $\mathrm{L}$ forms must await adaptation of these organisms to a broth medium.

Colony morphology, when examined under low magnification $(\times 45)$, varied both with $\mathrm{L}$ forms derived from different parents and with different $\mathrm{L}$-form colonies from the same parent. Factors such as type of medium employed, age of culture and amount of inoculum were important determinants. Under higher magnification granular bodies, intermediate size bodies and peripheral vacuoles were similar to those seen in other $\mathrm{L}$ forms. Since colony appearance varies within a given strain and structural elements are similar to $\mathrm{L}$ forms of other bacteria, macroscopic and microscopic colony morphology are not reliable differential tools in the identification of $\mathrm{L}$ forms of meningococci.

The specificity of serological grouping of group B meningococci is probably determined by a polysaccharide-polypeptide complex (Menzel \& Rake, 1942); however, its site within the bacterium has not been determined. Because $\mathrm{L}$ forms of group B meningococci did not agglutinate with known group B antisera, the $\mathrm{L}$ form may lack this complex; and since $\mathrm{L}$ forms do not have a cell wall, the site of this complex is probably in the cell wall of the parent group B meningococcus. Other immunological studies to define the antigenic complexes of both the parent and the $\mathrm{L}$ form of group $\mathrm{B}$ meningococci are in progress.

The importance of (1) the use of a simplified medium to exclude sulphadiazine competitors, and (2) the standardization of the inoculum size have been previously emphasized in the determination of sulphadiazine sensitivities of meningococci (Jewell, 1958; Feldman, 1965). Because a simplified medium does not support Lform growth, sulphadiazine sensitivities were determined on penicillin-free BRHIA. 
The minimum inhibitory concentrations of the $L$ form and its respective parent were identical on this complex medium. Subsequently the m.i.c., both of the same parent and of the revertant from the respective $\mathrm{L}$ form, was determined on MuellerHinton agar (Table 3). This value was approximately one-tenth that observed on BRHIA. The discrepancy in these values emphasizes the importance of considering the effects of complex media when determining sulphadiazine sensitivity of $\mathbf{L}$ forms. The authors hope that with the application of this information and the future elucidation of more definitive tests for identification, the possible role of these $\mathbf{L}$ forms in human meningococcal disease can be defined.

The authors wish to thank Mr C. Burris for his technical assistance, Mr J. McClain, Medical Audio-Visual Department, for the photography of Figs. 1-5, and Dr E. A. Mortimer, Western Reserve University School of Medicine, Cleveland, and Mr J. Evans for their helpful advice.

\section{REFERENCES}

Bristow, W. M., Van Peenen, P. F. D. \& Volk, R. (1965). Epidemic meningitis in naval recruits. Am. J. publ. Hlth, 55, 1039.

Brown, J. W. \& Condit, P. K. (1965). Meningococcal infections. Fort Ord and California. Calif. Med. 102, 171.

Catlin, B. W. \& Cunningham, L. S. (1961). Transforming activities and base contents of deoxyribonucleate preparations from various Neisseriae. J. gen. Microbiol. $26,303$.

Communicable Disease Center (1964). Morbidity and Mortality, weekly report, 13, 438. Dienes, L. \& Weinberger, H. J. (1951). The L forms of bacteria. Bact. Rev. 15, 245.

Dienes, L., Bandur, B. M. \& Madoff, S. (1964). Development of L-type growth in Neisseria gonorrhoeae cultures. $J$. Bact. 87, 1471.

EDWARD, D. G. FF (1950). An investigation of the biological properties of organisms of the pleuropneumonia group, with suggestions regarding the identification of strains. $J$. gen. Microbiol. 4, 311.

EDward, D. G. FF. (1953). A difference in growth requirements between bacteria in the L-phase and organisms of the pleuropneumonia group. J. gen. Microbiol. 8, 256.

Evans, J. R., Hunter, D. H., CARY, S. G. \& Rust, J. H. (1964). Simplified method for determination of sulfadiazine sensitivity and fermentation reactions of Neisseria meningitidis. Bact. Proc. p. 56.

Feldman, H. A. (1965). Retaliation by meningococci. Lancet, $i, 436$.

Jewell, R. P. (1958). Studies to find an inhibitor-free media for sensitivity on the sulfonamides. Am. J. med. Technol. 24, 371.

Landman, O. E. \& Halle, S. (1963). Enzymically and physically induced inheritance changes in Bacillus subtilis. J. molec. Biol. 7, 721.

Lederberg, J. \& St Clair, J. (1958). Protoplasts and L-type growth of Escherichia coli. J. Bact. 75, 143.

Madoff, S. (1960). Isolation and identification of PPLO. Ann. N.Y. Acad. Sci. 79, 383.

MAdofF, S. \& Dienes, L. (1958). L forms from pneumococci. J. Bact. 76, 245.

Menzel, A. E. O. \& RAKE, G. (1942). Studies on meningococcal infection. XII. Immunochemical studies on meningococcus type II. J. exp. Med. 75, 437.

RotTa, J., Karakawa, W. W. \& KraUSe, R. M. (1965). Isolation of L forms from group A streptococci exposed to bacitracin. J. Bact. 89, 1581.

Sharp, J. T. (1954). L colonies from hemolytic streptococci: new technic in the study of $\mathrm{L}$ forms of bacteria. Proc. Soc. exp. Biol. Med. 87, 94.

Sмxтн, P. F. (1964). Comparative physiology of pleuropneumonia-like and L-type organisms. Bact. Rev. 28, 97.

WARD, J. R. \& Martin, C. H. (1962). Production of L phase variants of bacteria with cycloserine. Proc. Soc. exp. Biol. Med. 111, 156.

Williams, R. E. O. (1963). L forms of Staphylococcus aureus. J. gen. Microbiol. 33, 325. 


\section{EXPLANATION OF PLATES}

\section{Plate 1}

Fig. 1. A penicillin gradient plate showing a band of L-form colonies between the trough and bacterial growth; $\times 0.8$.

Fig. 2. Enlargement of an area of L-form growth on a penicillin gradient plate. Non-propagating, small, rough, bacterial colonies also present; $\times 16$.

Fig. 3. Two-day growth of L-form colonies with well-demarcated cores and sharply defined peripheries; $\times 24$.

Fig. 4. Two-day growth of L-form colonies demonstrating variation in size and structure; $\times 16$.

\section{Plate 2}

Fig. 5. An L-form colony with a double core and peripheral vacuoles. Dienes's stain with light microscopy; $\times 320$.

Fig. 6. One-day growth of an L-form colony. Periphery in focus demonstrating many intermediate size phase-dense bodies. Dienes's stain with phase microscopy; $\times 1600$.

Fig. 7. One-day growth of the same L-form colony shown in Fig. 6. Core in focus demonstrating many granular bodies. Dienes's stain with phase microscopy; $\times 1600$.

Fig. 8. Two-day growth of an L-form colony. Periphery in focus demonstrating well defined vacuoles. Dienes's stain with phase microscopy; $\times 1600$. 
Journal of General Microbiology, Vol. 44, No. 1

Plate 1


R. B. ROBERTS AND R. G. WITTLER

(Facing $p$. 148) 

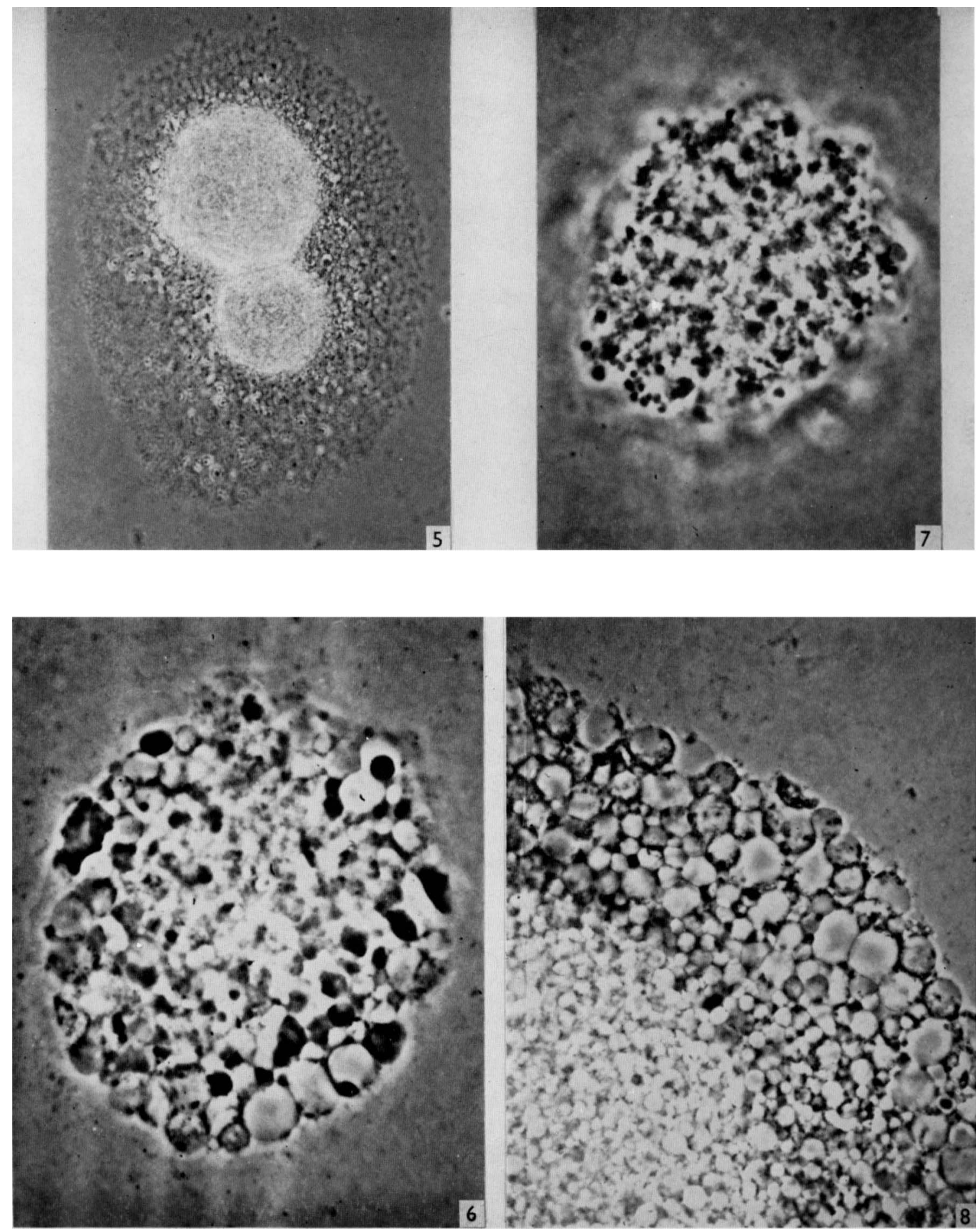

R. B. ROBERTS AND R. G. WITTLER 